\title{
A Correlational Study: Code of Ethics in testing and EFL Instructors' Professional Behavior
}

\author{
Hamid Ashraf \\ Asst. Prof., Department of English, Torbat-e Heydarieh Branch, Islamic Azad \\ University, Iran, hamid.ashraf.elt@gmail.com
}

\section{Zahra Kafi}

PhD student, corresponding author, English Department, Torbat-e Heydarieh Branch, Islamic Azad University, Iran, zahra.kafi.p@gmail.com

\section{Azaam Saeedan}

PhD student, Department of English, Torbat-e Heydarieh Branch, Islamic Azad University, Iran, azam.saeedan@yahoo.com language institutions to see how far adhering to these ethical codes will result in EFL teachers' professional behavior. Therefore, $300 \mathrm{EFL}$ instructors teaching at English language schools in Khorasan Razavi Province, Zabansara Language School, as well as Khorasan Shomali Province, Kish Air and Fatemi Language Schools were selected randomly to fill out two questionnaires, Professional Behavior Inventory as well as Code of Ethics in Testing Inventory. Moreover, a structured interview was employed among the participants of the study, 30 instructors, to obtain a more in depth data. After the qualitative and quantitative results were analyzed by running Multiple Regression, it was revealed that "Considering Content" as one of the subcategories of code of ethics in testing could be considered as a significant predictor of teachers' professional behavior. Finally, limitations of the study and suggestions for further research are discussed.

Keywords: code of ethics in testing, professional behavior, EFL instructors, language institution, teachers

\section{INTRODUCTION}

Regarding professional behavior; respect for others, commitment to quality, responsibility and personal integrity can be mentioned as some of its subcategories. But on top of all these aspects comes the role of code of ethics, which paves the way for stepping into a "profession" more professionally (Faculty of Engineering, 2000). In fact, professional behavior is all about adhering to code of ethics in a workplace as a member

Citation: Ashraf, H., Kafi, Z., \& Saeedan, A. (2018). A Correlational Study: Code of Ethics in testing and EFL Instructors' Professional Behavior. International Journal of Instruction, 11(1), 283-294. https://doi.org/10.12973/iji.2018.11120a 
of the community. Therefore, one of the responsibilities of a teacher as a professional behavior is developing an "ethical, fair, useful, feasible, and accurate" test/ assessment (Green, Johnson, Kim, \& Pope, 2007). On the other hand, the ethical codes developed shouldn't be that much hypothetical and far fetching. They must be developed in accordance with a specific teaching/learning context consequently having a clear-cut framework suitable for practicing professional behavior in (Gipps, 1994). As a result, code of ethics in conduct bring about various facets of professional behavior within a teacher such as, feeling responsible for the tests which are developed, about scores, being up to date about the new ways of testing and assessing and so forth and so like.

"You know it when you see it. You certainly know it when you see its antithesis. And you know it when you are expecting to see it, but do not"(Hammer, 2000, p. 455). Professional behavior in all working places has got a crucial role which needs to be pondered upon by all executives and clerks and more specifically here EFL instructors, an elusive concept which can be misleading unless great attention is paid to what professional behavior means in a situation, to be defined clearly. What does it mean truly when we talk about a behavior which is professional? Why some colleagues in a particular workplace can be considered as high achievers more than their counterparts? What are the building blocks that constitute such a professional behavior?

Considering all the aforementioned issues in perspective, the present study has aimed at delving the code of ethics in testing in English language institutions to see how far adhering to these ethical codes will result in EFL teachers' professional behavior. Thus, finding out to what extends code of ethics in testing contribute to instructors' professional behavior in the realm of English language teaching, possessing any probable predictions or correlations.

\section{Research Questions}

To gain the goals of the present study the following research questions were posed regarding the quantitative phase:

Q1: Is there any significant relations between Iranian EFL instructors' professional behavior and adhering to code of ethics in testing?

Q2: Can the subcategories of code of ethics in testing be considered as some probable predictors of Iranian EFL instructors' professional behavior?

Also, the following questions were raised for the structured interview, qualitative phase. The obtained answers are discussed in the Results Section.

Q1: what sorts of code of ethics in testing you have employed till now while developing tests?

Q2: Do you think that conducting code of ethics in testing leads to a professional behavior? How and why? 


\section{Research Hypotheses}

To come up with reasonable results based on the aforementioned research questions, quantitative phase, the following null hypotheses were raised. It is worth mentioning that in order not to be subjective or biased about the process of the study, data collection, and the results, null hypotheses are posed.

HO1: There is no significant relation between Iranian EFL instructors' professional behavior and adhering to code of ethics in testing.

HO2: The subcategories of code of ethics in testing cannot be considered as some probable predictors of Iranian EFL instructors' professional behavior.

\section{REVIEW OF THE RELATED LITERATURE}

\section{Professional Behavior}

One of the aspects of a professional behavior for an instructor is classroom management. That is a teacher who is able to provide students with a creative, relaxing environment in which the learners are emotionally and academically supported can be considered as an important issue in a professional way of teaching subject matters. Therefore, the present study considers professional behavior as setting the instructional goals and activities in a way which are in accordance to the students' level and needs. And on top of that to have the knowledge and skills of how to test students' knowledge ethically, which leads to a better achievement on part of learners (Yazdanmehr \& Akbari, 2015; Brophy, 1979). Thus, professional behavior is all about when, how and what to do to fit into a particular context of teaching and learning. Moreover, in another study done by Hammer (2000) structural attributes of professions as well as professionals consisted of a specialized body of knowledge as well as skills, special socialization among students, certifications, professional associations, governance by peers, social prestige, crucial service to community, and code of ethics along with having autonomy.

On the other hand, professionalism can be delved according to students' attitudes and behaviors which can be impacted by educational issues such as " the values and behaviors that students bring into professional programs, role models in the professional and academic environments, and the environments themselves" building positive or negative social/ professional attitude (Hammer, 2000). Besides, professional development/behavior all takes place by learning through the passage of time. Previous studies have reached to the idea that it can be gained through rstudies done within the same realm have pin pointed the fact that some factors such as macro societal conditions along with micro-contexts that teachers are in greatly affect teachers on the process of reaching to a professional behavior or development (Avalos, 2011).

Moreover, teaching has been viewed as a behavior towards professionalism which considers the point of providing novice teachers with activities through which they can improve skills and competencies that experienced professionals commonly use (Richards \& Nunan, 1990; Salmani Nodoushan, 2006, 2008, 2011; as cited in Kanakri, 2017). And this dynamic professionalism doesn't take place unless teachers and students 
participate in special progressive social contexts within which they continuously construct and reconstruct their knowledge and theory (Salmani Nodoushan \& Daftarifard, 2011).

In addition, providing teachers with technological classrooms within which they can make use of open access materials as well as the related literature can improve another dimension of their professional behavior, coming to be more autonomous and selfdirected (Zuppa \& Rezzano, 20016). Also, Brown (2016), a professional in the field of applied linguistics, has done a reflective study on his professional growth and has reached to three basic ideas through the path: " people have played an important role at all the stages of his career, we all tend to stereotype each other professionally, and he has enjoyed all the minutes of the ride towards professionalism", which means that professional behavior is at time co-constructed too.

\section{Code of Ethics}

Considering instructors' professional behavior and code of ethics in testing very few studies have been done in the aforementioned realm. In most of the educational settings code of ethics has been viewed as a standardized test which informs the instructors, students, parents and all the others who are to some extents involved in developing a test. Consequently, testing must be handled in a way that includes security, preparation, administration, and scoring, analysis and report. To reach to such a purpose a test developer/instructor should adhere to ethical codes in testing and avoid the unethical practices (Testing Code of Ethics, 2000). On the other hand, there's always a problem accompanied by code of ethics in testing. That is, there is no consistent agreement upon tests following ethical standards (Thorndike, Cunnningham, Thorndike, \& Hagen, 1991; as cited in Green, Johnson, Kim, \& Pope, 2007). In addition, another study has been done by Childs and Umezawa (2009) to find out what would grade 3 teachers do in case they were faced with test administration dilemmas. Many of the instructors in the study mentioned that they would not follow the test administration instructions and their reasons included: to support the students to reach to their best talent, to ensure a beneficial testing experience for the pupils, and to continue and follow their pedagogical routines and their connections with the students. The results pin point the ethical dilemmas instructors might experience while proctoring tests. Moreover, a research has been done by Zhang and Burry-Stock (2003) to investigate about instructors' assessment practices across their teaching levels, content areas, and teachers' self-perceived assessment skills as a function of teaching experience and measurement training. The outcome has revealed that as the grade level increases teachers' concern for employing a high, ethical quality test and assessment increases as well. Also, regardless of teachers' teaching experience, the ones who have had the experience of being in measurement training were much successful and aware about ethics in testing and how to develop standardized tests and assessment. Therefore, not just being experienced in teaching is enough for an EFL instructor, but being aware of code of ethics as well as practicing them are mandatory as part of a professional behavior. 


\section{METHOD}

\section{Participants and Setting}

A sample of 300 Iranian EFL instructors teaching at English Language Schools in Khorasan Razavi Province, Zabansara Language School, as well as Khorasan Shomali Province, Kish Air and Fatemi Language Schools, Iran, took part in the study randomly. $65 \%$ of them were females and $35 \%$ were male ones. In addition, they held M. A. degrees mostly and then B. A. degrees in Teaching English, English Translation and Literature. Besides their age ranged from 25 to 35 .

\section{Instrumentation}

\section{Code of Ethics in Testing Inventory}

CETI is a researcher made questionnaire, which consists of 46 items, developed by Motallebzadeh et al. (in press). It aims at eliciting the participants' awareness about code of ethics in testing, which has been cross-checked and peer reviewed by some experts in the field of testing and teaching English as a foreign language. Each item consists of 5 choices ranging from "Strongly agree" to "Strongly disagree", Likert Scale. In addition, the scale consists of 8 subcategories as: 1) Considering aims and values (why), 2) Considering contents (what), 3) Considering Practical aspects (how), 4) Fairness and honestly, 5) Keeping professional knowledge, 6) Collaboration, 7. Adherence to regulations, and 8) respect and professional relationship with students. Regarding the construct validity of the present inventory, Exploratory Factor Analysis with principal component analysis and varimax rotation has been applied. In addition, to examine the validity of the CET questionnaire, Confirmatory Factor Analysis has been employed. In addition, the reliability of the questionnaire was estimated through running Cronbach's alpha that obtained a reliability coefficient of .816. It's worth mentioning that structural equation modeling (SEM) with multiple indicators was employed to examine the validity and reliability of Codes of Ethics in Testing Inventory.

\section{Professional Behavior Inventory}

The questionnaire consists of 25 items related to EFL teachers' professional behavior to find out how frequent they do each of the activities mentioned in the items, ranging from 1 to 5 (never to always). The questionnaire is a researcher made one developed by Kafi and Motallebzadeh (2016) which possesses a high validity and a reliability of .850 . Also, the items were developed based on principle constructs related to professional behavior consisting of "Responsibility, Communication, Interpersonal skills, Professionalism, Effective use of time and resources, Stress management, and Intrapersonal skills".

\section{Structured Interview}

Regarding the qualitative phase of the present study the researchers conducted a structured interview to gather some more in depth data. Therefore, 30 participants from the ones who had taken the questionnaires previously were interviewed in their workplaces. As most of the participants were not willing for their voices to be recorded, 
the interviewers took notes of their answers to each question. The interview questions consisted of:

Q1: what sorts of code of ethics in testing you have employed till now while developing tests? (They can be among the codes/criteria presented in the questionnaire or other issues you believe are crucial when developing tests)

Q2: Do you think that conducting code of ethics in testing leads to a professional behavior? How and why?

\section{Procedure}

For gaining the results of the study the aforementioned questionnaires, Code of Ethics in Testing Inventory along with Professional Behavior Inventory were handed to participants of the study to be filled in within 20 minutes. By the time the questionnaires were collected, the researchers conducted the structured interview within the participants of the study to delve more into their ideas towards professional behavior and code of ethics in testing. For not missing the details of the interview the researchers took exact notes of the EFL instructors' ideas about the questions which were raised and discussed. When data gathering was over regarding both the qualitative and quantitative phases of the study, the researchers analyzed the data using SPSS Software and more specifically Multiple Regression.

\section{Study Design}

As the study has aimed at investigating whether code of ethics in testing can be considered as probable predictors of EFL instructors' professional behavior in both qualitative and quantitative ways therefore the design of the study is a mixed one.

\section{FINDINGS}

\section{CFA model of the Code of Ethics in testing Inventory}

A brief outlook of the model regarding the aforementioned questionnaire which has been conducted in the study done by Motallebzadeh et al. (in press, p. 11):

"In order to examine the validity of the Codes of Ethics inventory, Confirmatory Factor Analysis was used. To check the model fit, goodness of fit indices was used. The model with all factor loadings can be seen in Figure 1. Goodness of fit indices can be seen in Table 2. In this study, $\chi^{2} / \mathrm{df}$, GFI, CFI, and RMSEA were used. To have a fit model, $\chi^{2} / \mathrm{df}$ should be less than 3 , GFI and TLI should be above .90, and RMSEA should be less than .08. As Table 2 shows, all the fit indices are within the acceptable range. Therefore, the scale enjoyed high validity". 


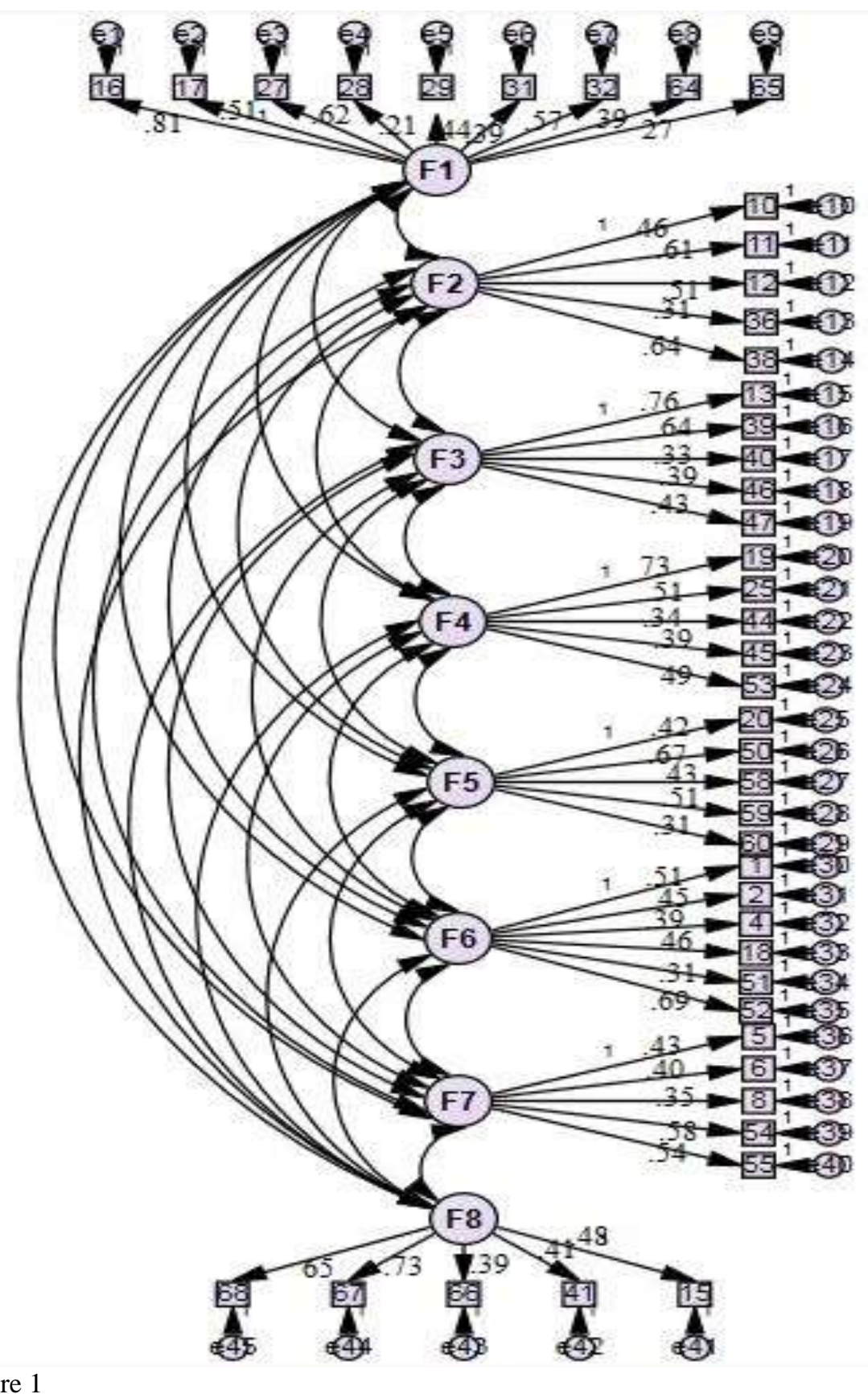

Figure 1

The model with all factor 


\section{Quantitative Data}

Table 1

Regression analysis summary for predicting professional behavior

\begin{tabular}{|c|c|c|c|c|}
\hline \multicolumn{2}{|c|}{ Coefficients } & \multirow{2}{*}{$\begin{array}{c}\begin{array}{c}\text { Standardized } \\
\text { Coefficients }\end{array} \\
\text { Beta } \\
\end{array}$} & \multirow{3}{*}{$\begin{array}{l}\mathrm{T} \\
14.161\end{array}$} & \multirow{3}{*}{$\begin{array}{l}\text { Sig. } \\
\\
.000\end{array}$} \\
\hline & & & & \\
\hline \multirow[t]{9}{*}{1} & (Constant) & & & \\
\hline & Collaboration & -.046 & -.789 & .430 \\
\hline & Considering aims \& values & .000 & .006 & .995 \\
\hline & Considering content & .142 & 2.438 & .015 \\
\hline & Considering practical aspects & .100 & 1.709 & .088 \\
\hline & Fairness \& honesty & .000 & .006 & .996 \\
\hline & Keeping professional knowledge & .055 & .931 & .353 \\
\hline & Adherence to regulations & .031 & .532 & .595 \\
\hline & $\begin{array}{l}\text { Respect \& professional } \\
\text { relationship with students }\end{array}$ & .103 & 1.753 & .081 \\
\hline
\end{tabular}

To sum up, the present study endeavored to investigate the possible significant correlations of professional behavior with measures of code of ethics in testing which had 8 subcategories.

The participants of the research were 300 EFL instructors among which $65 \%$ of them were female and $35 \%$ were male ones holding M. A. degrees and then B. A. degrees in English. Besides their age ranged from 25 to 35 .

To this end, Multiple Regression through SPSS Software was employed to find out the role of the independent variables, code of ethics in testing along with its subcategories, in regard with the dependent variable, professional behavior. Initial analyses revealed no violation of the assumptions of normality, linearity, multicollinearity, as well as homoscedasticity.

Considering all the independent variables, only "Considering Content" ,as one of the subcategories of code of ethics in testing, had the greatest contribution for predicting the dependent variable, professional behavior, which was completely significant $($ Beta $=.142, \mathrm{p}<.05)$. The analysis illustrated that the other independent variables had some degrees of contribution for predicting professional behavior but they weren't significant ( $\mathrm{p}>.05)$ (Table 1).

Results displayed that the total variance explained by the model as a whole was $5.6 \%$, $\mathrm{R}=.236, \mathrm{R}^{2}=.056, \mathrm{p}<.05, R^{2}$ Adjusted $\left.=.030\right)$ (Table 2).

The regression coefficients in the following analysis were specifically significant at the level of .05 or below that. 


\section{Qualitative Data}

Tablo 2

Model summary

\begin{tabular}{lcccc}
\hline Model & $\mathrm{R}$ & $\mathrm{R}^{2}$ & Adjusted $\mathrm{R}^{2}$ & \multicolumn{1}{c}{ Sig. } \\
\hline 1 & $.236^{\mathrm{a}}$ & .056 & .030 & $.031^{*}$ \\
\hline a. Predictors: (Constant), 1) Considering aims and values (why), 2) Considering contents \\
(what), 3) Considering Practical aspects (how), 4) & Fairness and honestly, 5) Keeping \\
professional knowledge, 6) Collaboration, & 7. Adherence to regulations, and 8) respect and \\
professional relationship with students & & \\
$* \mathrm{p}<.05$.
\end{tabular}

Having gathered the qualitative data through the structured interview, the following results were revealed regarding each question. In addition, it is worth mentioning that as it is a structured interview, following the principals of mixed method design, the questions as well as the focus of the interview are pre-determined.

Q1: what sorts of code of ethics in testing you have employed till now while developing tests?

Most of the participants stated that when constructing tests they developed items which were in accordance with the "quality of teaching". It means that if they haven't taught a particular topic in depth, they will not develop so many tests out of that specific part or at least not developing difficult questions. Also, they mentioned that the "content of the test must be in line with the content of the materials". In addition, they try to develop tests moving from easy to hard questions which are suitable for all kinds of students with various skills and abilities. Moreover, some of the other issues that they adhere to while developing tests were: avoid developing tests which made students feel humiliated, make use of the test results as a reflective way to assess their own teaching and students' learning, and being fair when scoring the tests and passing students' final marks.

Q2: Do you think that conducting code of ethics in testing leads to a professional behavior? How and why?

Regarding the participants' answers for the aforementioned question, most of them believed that testing and more specifically "developing tests as a part of teaching profession greatly influences teaching and learning". That is in case a teacher isn't able or at times doesn't pay attention to ethics in testing, this shortcoming will affect the other sides of teaching profession such as their teaching, students' learning, students' perspective towards the teacher and testing and some of the other related issues. Therefore, adhering and conducting code of ethics in testing, as a responsibility for teachers, fulfills one part of the professionalism regarding teachers' behavior which directly and indirectly affects the other parts/sections as well.

\section{DISCUSSION AND CONCLUSION}

Considering instructors' professional behavior and code of ethics in testing very few studies have been done in the aforementioned realm. In most of the educational settings 
code of ethics has been viewed as a standardized test which informs the instructors, students, parents and all the others who are to some extents involved in developing a test. On the other hand, there's always a problem accompanied by code of ethics in testing. That is, there is no consistent agreement upon tests following ethical standards (Thorndike, Cunnningham, Thorndike, \& Hagen, 1991; as cited in Green, Johnson, Kim, $\&$ Pope, 2007).

Moreover, a research has been done by Zhang \& Burry-Stock (2003) to investigate about instructors' assessment practices across their teaching levels, content areas, and teachers' self-perceived assessment skills as a function of teaching experience, professional behavior, and measurement training. The outcome has revealed that as the grade level increases teachers' concern for employing a high, ethical quality test and assessment increases as well.

Consequently, the present study has applied two questionnaires, Professional Behavior Inventory \& Code of Ethics in Testing Inventory, along with a structured interview to gather data from Iranian EFL teachers.

Results related to the first research question showed that $5.6 \%$ of the variance in professional behavior is explained by the independent variables.

Regarding the second research question, it was also revealed that "Considering Content" as one of the subcategories of code of ethics in testing could be considered as the only significant predictor of professional behavior, $(p<.05)$. Thus, the other subcategories of code of ethics in testing like: Considering aims and values (why), Considering Practical aspects (how), Fairness and honestly, Keeping professional knowledge, Collaboration, Adherence to regulations, and respect and professional relationship with students weren't considered as significant predictors of teachers' professional behavior $(\mathrm{p}>.05)$.

Therefore, the results of the research are in line with Yazdanmehr \& Akbari (2015) as well as Brophy (1979) who have stated that instructional goals and activities which are set in accordance to the students' level, needs, and content is one of the other subcategories of having a professional perspective towards teaching, leading to a better achievement on part of learners. Thus, professional behavior is all about when, how and what to do to fit into a particular context of teaching and learning.

Having a closer look at the obtained result, it becomes vivid that the aforementioned subcategories of code of ethics in testing gained no significant relation with the professional behavior not acting as the predictors of the dependent variable. That is as mentioned throughout the literature review just having a high level of teaching experience doesn't lead to acting professionally and adhering to code of ethics.

\section{Suggestions for Further Research}

At the end, the short comings in the results of the present study and context of research could be a suggestion for further research. It means researchers can have some training courses for EFL teachers of what is truly meant by professional behavior and code of ethics in testing. In addition, a cause and effect study could be employed to find out 
whether their awareness has changed after the training courses or not. Moreover, new studies can be done to compensate for the limitations of the present study. Better to say, conducting researches at universities or other cities or countries. Also, participants could be selected randomly from instructors teaching at universities and English language schools and compare the results to find out which group possesses a higher professional behavior and practice ethical issues in testing more and why. On the other hand, a study can be done to pinpoint the educational practices that deprive teachers and learners from a sheer conduct of professionalism (Salmani Nodoushan \& Pashapour, 2016).

\section{REFERENCES}

Avalos, B. (2011). Teacher professional development in Teaching and Teacher Education over ten years. Teaching and Teacher Education, 27,10-20.

Brophy, J. E. (1979). Teacher behavior and its effects. Journal of Educational Psychology, 71, 733-750.

Brown, J. D. (2016). A professional reflection: Forty years in applied linguistics. International Journal of Language Studies, 10 (1), 1-14.

Childs, R. A., \& Umezawa, L. (2009). When the teacher is the test proctor. Canadian Journal of Education 32 (3), 618-651.

Faculty of Engineering. (2000). Standards for professional behavior. University of Victoria.

Gipps, C. V. (1994). Beyond testing: Towards a theory of educational assessment. Washington, DC: The Falmer Press

Green, S., Johnson, R., Kim, D., \& Pope, N. (2007). Ethics in classroom assessment practices: Issues and attitudes. Teaching and Teacher Education, 23, 999-1011.

Hammer, D. P. (2000). Professional attitudes and behaviors: The "A's and B's" ofProfessionalism. Manuscript based on the presentation at the Teachers Seminar “Civility/Professionalism,".

Kafi, Zb., \& Motallebzadeh, Kh. (2016). Language teachers' aspects of identity and their professional behavior: Identity, behavior and professional change. Modern Journal of Language Teaching Methods, 6(2).

Kanakri, A. (2017). Second language teacher education: Preparing teachers for the needs of second language learners. International Journal of Language Studies, 11(1), 63-94.

Motallebzadeh, Kh., Hosseiniah, M., Kafi, Zh., \& Kazemi, S. (in press). Code of ethics in testing inventory: Investigating EFL instructors' perspectives.

Richards, J. C., \& Nunan, D. (1990). Second language teacher education. New York, NY: University of Cambridge. 
Salmani Nodoushan, M. A. (2006). Language teaching: State of the art. Asian EFL Journal, 8(1), 169-193.

Salmani Nodoushan, M. A. (2008). The role of metacognition in the language teaching profession. Journal on Educational Psychology, 2(1), 1-9.

Salmani Nodoushan, M. A. (2011). Reflective teaching in English as a Foreign Language classes: An overview. Journal on School Educational Technology, 6(3), 1-6.

Salmani Nodoushan, M. A., \& Daftarifard, P. (2011). Globalized classroom, emancipatory competence, and critical pedagogy: A paradigm shift. In R. V. Nata, Progress in Education, 147-162.

Salmani Nodoushan, M. A., \& Pashapour, A. (2016). Critical pedagogy, rituals of distinction, and true professionalism. Journal of Educational Technology, 13(1), 29- 43.

Testing Code of Ethics. (2000). Authority G.S. 115C-12(9)c.; 115C-81(b)(4).

Thorndike, R., Cunnningham, G., Thorndike, R., \& Hagen, E. (1991). Measurement and evaluation in psychology and education (5th ed.). New York: McMillan.

Yazdanmehr, E., \& Akbari, R. (2015). An expert EFL teacher's class management. Iranian Journal of Language Teaching Research 3(2), 1-13.

Zhang, Z., \& Burry-Stock, J. A. (2003).Classroom assessment practices and teachers' self perceived assessment skills. Applied Measurement in Education, 16(4), 323-342.

Zuppa, 1., \& Rezanno, S. (2016). The construction of the role of the teachers in academic articles on ICT and education: An exploratory analysis of experiential and interpersonal meanings. International Journal of Language Studies, 10(3), 5-22. 